\title{
Construção Curricular: um estudo sobre Brasil e Peru
}

\author{
Dr. ${ }^{\text {a }}$ Ivanete, Bellucci Pires de Almeida \\ Centro Estadual de Educação Tecnológica Paula Souza, São Paulo, Brasil \\ ivanete.bellucci@fatec.sp.gov.br \\ Gilson, Rede \\ Centro Estadual de Educação Tecnológica Paula Souza, São Paulo, Brasil \\ gilson.rede@cps.sp.gov.br
}

\section{Resumo}

O objetivo deste trabalho é detalhar os procedimentos para a construção de componentes curriculares de cursos técnicos de nível médio oferecidos no Brasil e no Peru, tomando por base o Centro Estadual de Educação Tecnológica Paula Souza (Ceeteps) e o Serviço Nacional de Adestramento em Trabalho Industrial (Senati), respectivamente. Corroboram este estudo as ações de internacionalização da Educação Profissional e Tecnológica (EPT), focadas principalmente no desenvolvimento de competências requeridas pelo mercado de trabalho. A troca de experiências e práticas entre países de características socioeconômicas convergentes, cujos setores produtivos demandam mão-de-obra qualificada, é primordial diante dos desafios impostos pela globalização. A pesquisa possui abordagem qualitativa de caráter exploratório, tendo como premissa a análise das políticas públicas de educação no Brasil e no Peru, além das diretrizes praticadas por instituições de EPT dos dois países. Os dados que embasam este trabalho foram extraídos das leis vigentes nos países, seus respectivos censos escolares, bibliografias e informações constantes dos sites das instituições analisadas. De posse destes registros, verifica-se similaridades nas suas práticas, indicando que os cursos técnicos de nível médio devem ser concebidos de modo a garantir não apenas a formação cidadã dos alunos, mas também o desenvolvimento de habilidades e competências voltadas à prática profissional. Para isso, é relevante consultar os vários atores envolvidos na oferta dos cursos - escolas, professores, empresas - validando seu oferecimento. Nota-se que, embora os sistemas de ensino dos dois países possuam convergências, também são dotados de características próprias. Baseando-se nisso, o trabalho é estruturado em seções que abordam a EPT brasileira, a legislação e práticas peruanas e sua contextualização, discutindo ao final os pontos principais de convergência entre aquilo que é adotado pelos países, apontando para um futuro estudo mais aprofundado em termos de comparação e internacionalização da EPT.

\section{Abstract}

The objective of this paper is to detail the procedures for the curricular construction of medium- level technical courses offered in Brazil and Peru, based on Centro Estadual de Educação Tecnológica Paula Souza (Ceeteps) and Servicio Nacional de Adiestramiento en Trabajo Industrial (Senati), respectively. In this study, the internationalization actions of the Professional and Technological Education (PTE) focus on the development of skills required by the job market. The exchange of experiences and practices among countries with convergent socioeconomic characteristics, whose productive sectors demand skilled labor, is paramount to the challenges imposed by globalization. The research has a qualitative approach of exploratory nature, having as premise the analysis of public education policies in Brazil and Peru, in addition to the guidelines practiced by its PTE institutions. The data based on this work were extracted from the laws in force, their respective school censuses, bibliographies and information contained in the sites of the institutions analyzed. In possession of these records, similarities in their practices are verified, indicating that the technical courses of intermediate level must be conceived in order to guarantee not only the citizen education of the students, but also the development of skills and competences oriented to the labor practice. For this, the various actors involved in the offer are consulted - schools, professors, companies - validating their offer. It is observed that, although the education systems of the two countries have convergences, they are also endowed with their own characteristics. Based on this, the work is structured into sections that address Brazilian and Peruvian PTE and its contextualization, discussing at the end the main points of convergence between what is adopted by the countries, pointing towards a future more in-depth study on comparison and internationalization of the PTE.

Palavras-chave: Educação Profissional e Tecnológica, Educação Comparada, competência, construção curricular, internacionalização.

Keywords: Professional and Technological Education, Comparative Education, skill, curricular construction, internationalization.

http://doi.org/10.25145/c.educomp.2018.16.093 
Este estudo toma por base o processo de formulação curricular adotado pelo Centro Estadual de Educação Tecnológica Paula Souza (Ceeteps), em São Paulo, Brasil, com o propósito da internacionalização desses procedimentos ao compará-los com outra instituição de ensino profissional de nível médio, situada no Peru (Serviço Nacional de Adestramento em Trabalho Industrial - Senati), cujos resultados apontam para uma direção comum às instituições que oferecem Educação Profissional e Tecnológica (EPT) na América Latina.

Pelo fato de os cursos técnicos de nível médio serem concebidos de modo a garantir a formação cidadã dos alunos e o desenvolvimento de competências ${ }^{1}$ técnicas, é latente a necessidade de consulta às instituições parceiras que oferecem esses cursos, bem como aos diversos atores envolvidos nesse processo, como escolas, comunidade regional, professores e empresas, validando a oferta para diferentes públicos. Neste movimento de reconhecer e formular o currículo, sua análise torna-se primordial, dada sua evidência e importância no sistema educacional.

A pesquisa proposta divide-se, em um primeiro momento, na confecção de um panorama do cenário da EPT no Brasil e no Peru, contemplando apontamentos de especialistas do assunto para que, fundamentalmente, seja possível compreender sua trajetória. Em seguida promove-se a análise e evolução do tema "Currículo", a possibilidade de sua internacionalização e a legitimidade de estudos de Educação Comparada.

A análise das legislações da EPT de Brasil e Peru também é parte integrante deste trabalho, de modo a pormenorizá-las para que seja possível identificar os pontos comuns dos regimentos, bem como o estudo do Currículo da Educação Profissional, com suas particularidades e essência próprias. Por fim, é abordada a sistemática de construção curricular adotada por Ceeteps e Senati e seus pontos de convergência.

\section{EDUCAÇÃO PROFISSIONAL NO BRASIL}

A Educação Profissional (EP) no Brasil tem origem baseada em experiências no treinamento de classes menos abastadas, que remontam ao século XVIII:

A história da educação profissional no Brasil tem várias experiências registradas nos anos de $1800 \mathrm{com}$ a adoção do modelo de aprendizagem dos ofícios manufatureiros que se destinava ao "amparo" da camada menos privilegiada da sociedade brasileira. As crianças e os jovens eram encaminhados para casas onde, além da instrução primária, aprendiam ofícios de tipografia, encadernação, alfaiataria, tornearia, carpintaria, sapataria, entre outros. (Brasil, 2009).

A forma pela qual a EP foi introduzida no país, mais especificamente em São Paulo, ao final do século XIX, é motivo de críticas por alguns autores, dentre eles Moraes (1996), que discutem e colocam em questão a origem elitista do ensino voltado ao setor produtivo, que primava pelos interesses dos proprietários do capital, indicando que "coube a uma facção da classe dominante [...] ser portadora de um projeto de mudança social, de construção de um novo padrão de sociabilidade condizente com o avanço das relações sociais capitalistas e, portanto, de uma nova escola" (p.131).

A Constituição da República Federativa do Brasil de 1937 apontou em seu artigo 129 o trato pioneiro dado ao ensino técnico, profissional e industrial:

À infância e à juventude, a que faltarem os recursos necessários à educação em instituições particulares, é dever da Nação, dos Estados e dos Municípios assegurar, pela fundação de instituições públicas de ensino em todos os seus graus, a possibilidade de receber uma educação adequada às suas faculdades, aptidões e tendências vocacionais. [...] (Brasil, 1937).

${ }^{1}$ Competência que se reflete em adquirir conhecimento pleno do assunto estudado. 
Passadas algumas décadas, um marco importante na EP é promulgado no país - Lei 5.692, de 11 de agosto de 1971, que fixou diretrizes e bases para o ensino de primeiro e segundo graus, cujo objetivo geral era proporcionar ao educando a formação necessária ao desenvolvimento de suas potencialidades como elemento de autorrealização, qualificação para o trabalho e preparo para o exercício consciente da cidadania (Brasil, 1971).

Pouco tempo depois, o parecer 45, de 1972, modificava a lei, remodelando o ensino médio profissionalizante - ação que, mediante sua implementação sem ampla discussão com a sociedade, também recebeu críticas de especialistas:

A resposta do governo foi intempestiva e burocrática, editando a Lei Federal n. ${ }^{\circ}$ 5.692/71 e, após seis meses, o Parecer n. ${ }^{\circ}$ 45/72, que transformava todo o Ensino Secundário em Ensino Técnico. Não havia qualquer estudo que justificasse tal decisão, nem as escolas (que, até então, ofereciam o Científico e o Clássico) estavam prontas, quanto às instalações e formação ou disponibilidade de professores, para oferecerem cursos técnicos.

A intenção de ampliar a formação profissional via Ensino Técnico não era má, mas havia uma presunção e arrogância imensas, em considerar que, num país com tantas e diferentes características regionais, poder-se-ia, de um ano para outro, implantar uma reforma de tal magnitude. (Araújo, 2015).

A Lei 5.692/71 sofreu alteração significativa por conta da Lei 7.044, de 18 de outubro de 1982, no que tange à profissionalização do ensino de segundo grau. Em seu Artigo $4^{\circ}$, parágrafo $2^{\circ}$, passou a indicar que "à preparação para o trabalho, no ensino de $2^{\circ}$ grau, poderia ensejar habilitação profissional, a critério do estabelecimento de ensino" (Brasil, 1971), extinguindo a obrigatoriedade da formação profissional nesta etapa escolar.

Marco educacional vigente, em 1996 foi implementada a Lei de Diretrizes e Bases, sob n. ${ }^{\circ}$ 9.394, que em sua Seção IV detalha os procedimentos de regência do ensino de nível médio. $\mathrm{O}$ artigo 36, modificado pela Lei n. ${ }^{\circ} 13.415$, de 2017 , discrimina a formulação dos currículos deste nível de escolaridade - objeto de pesquisa do presente trabalho - e indica as possibilidades de formação do aluno:

O currículo do ensino médio será composto pela Base Nacional Comum Curricular e por itinerários formativos, que deverão ser organizados por meio da oferta de diferentes arranjos curriculares, conforme a relevância para o contexto local e a possibilidade dos sistemas de ensino, a saber:

$$
\begin{aligned}
& \text { I - linguagens e suas tecnologias; } \\
& \text { II - matemática e suas tecnologias; } \\
& \text { III - ciências da natureza e suas tecnologias; } \\
& \text { IV - ciências humanas e sociais aplicadas; } \\
& \text { V - formação técnica e profissional. }
\end{aligned}
$$

$-1^{\circ} \mathrm{A}$ organização das áreas de que trata o caput e das respectivas competências e habilidades será feita de acordo com critérios estabelecidos em cada sistema de ensino.

$-2^{\circ}$ Revogado pela Lei . $^{\circ} 11.741$, de 2008.

- $3^{\circ} \mathrm{A}$ critério dos sistemas de ensino, poderá ser composto itinerário formativo integrado, que se traduz na composição de componentes curriculares da Base Nacional Comum Curricular BNCC e dos itinerários formativos, considerando os incisos I a V do caput. (Brasil, 1996).

Ao analisar a nova redação da Lei 9.394 de 1996, é conclusivo que as habilitações profissionais (ou cursos técnicos) são desenvolvidas pelas instituições de ensino de nível médio, cabendo-lhes a concepção de currículos que possam atender às demandas da sociedade. Brandão (2011), em artigo sobre a EP no contexto do Plano Nacional de Educação, a caracteriza como sendo uma modalidade que flutua entre a aprendizagem por conteúdos e temas, até a prática profissional junto ao setor produtivo: 
[...] quando se discute Ensino Profissional, entende-se que a formação para o trabalho exige maiores níveis de formação básica, geral e propedêutica, contrariando a ideia de que o Ensino Profissional se reduz à aprendizagem de habilidades técnicas. Por outro lado, continuam abertas as oportunidades de adaptação do trabalhador ao mercado de trabalho, a partir de uma formação adquirida por meio de cursos específicos de curta duração, que proporcionam também um aumento no seu nível de escolarização. Por um ou outro caminho, o Ensino Profissional passa a ser concebido como educação continuada, que, como tal, perpassa toda a vida do trabalhador. (Brandão, 2011).

Mesmo com os aprimoramentos propostos ao longo do tempo, o cenário apresentado sobre a EPT demonstra que esta não chegou ao seu ápice, tampouco apresenta-se finalizada, perfeita e universalizada, o que estimula propor análise de outros modelos educacionais que podem servir de base para futuras propostas de adequação àquilo vigente.

\section{EDUCAÇÃO PROFISSIONAL NO PERU}

Segundo a Lei Geral de Educação peruana, n. ${ }^{\circ} 28.044$, de 17 de julho de 2003, consta do seu artigo 40 que:

A Educação Técnico-Produtiva é uma forma de educação orientada a aquisição de competências laborais e empresariais em uma perspectiva de desenvolvimento sustentável e competitivo. Contribui para um melhor desempenho da pessoa que trabalha, a melhorar seu nível de empregabilidade e o seu desenvolvimento pessoal. Está destinada às pessoas que buscam uma inserção ou reinserção no mercado de trabalho e a alunos de Educação Básica. (Peru, 2003).

Modalidade análoga à EP de nível médio brasileira, a Educação Técnico-Produtiva no Peru está organizada em ciclos determinados pelas características e complexidades dos perfis técnico- profissionais e pelos requisitos acadêmicos específicos. Estes ciclos são organizados em módulos de acordo com as competências mais demandadas para exercício do trabalho.

O Ciclo Básico propõe ao aluno o desenvolvimento de competências profissionais e habilidades necessárias para executar trabalhos de menor complexidade. Este ciclo não pressupõe requisitos escolares, apenas a prévia identificação de capacidades básicas para a aprendizagem laboral.

O Ciclo Médio proporciona aos estudantes o aprendizado de competências necessárias para o exercício de uma atividade específica. Para ingressar neste ciclo são necessárias competências equivalentes ao nível de Educação Primária ou ao Ciclo Intermediário da Educação Básica Alternativa, este último equivalente à Educação de Jovens e Adultos (EJA) praticada no Brasil. É constituída por módulos convergentes que, em conjunto, constituem uma especialidade técnico- produtiva - esta, por sua vez, é delineada com base em um respectivo perfil profissional.

O Ministério de Educação do Peru estabelece os conteúdos e a duração de cada ciclo. A conclusão satisfatória de um ciclo dá direito a obtenção do correspondente título de técnico com menção na respectiva especialidade. Com isso, os estudantes podem continuar e concluir sua formação nos níveis da Educação Básica e consequentemente ascender à Educação Superior.

Há também o nível de Educação Superior Não Universitária, que consiste em cursos e programas educativos para aqueles cujo trabalho requer menor complexidade e não tenham completado a Educação Básica. Desse modo, o Ministério da Educação e autoridades regionais e locais coordenam ações junto ao Ministério do Trabalho e Promoção do Emprego, objetivando parcerias com o setor produtivo.

\section{O CURRÍCULO}

O tema "Currículo" ganhou importância no mundo da educação por ser um elemento com dimensões culturais e de poder no planejamento do processo escolar, e suas definições permeiam diversos escopos. Saviani (2016) o aborda de forma prática em sua operação nas instituições de ensino, contemplando sua efetividade, ao dizer que este "não é outra coisa senão essa própria escola em pleno funcionamento, isto é, mobilizando todos os seus recursos, materiais e humanos, na direção do objetivo que é a razão de ser de sua existência: a educação das crianças e jovens" (p.55). 
Sob a perspectiva da internacionalização do currículo, esta demonstra potencial de aproximar práticas institucionais amplas e diversas, voltadas ao aprendizado não só do aluno, mas das escolas como um todo. Esse processo se presta não somente à comparação entre dois agentes (países, geralmente), mas também a contribuir com o desenvolvimento e com a transferência de conhecimento que ultrapassa fronteiras e busca soluções comuns:

[...] a internacionalização pelo currículo trata de garantir a infusão das perspectivas multiculturais contidas e buscadas em/por todos em uma sala de aula ampliada, onde se podem articular diferentes conhecimentos, práticas e culturas. Dito de outra forma [...] desenvolve-se por atividades intelectuais que questionam a monocultura do saber, pela curiosidade em torno dos paradigmas ausentes, bem como pela identificação dos paradigmas emergentes e de suas possibilidades como subsídios ao currículo. (Luna, 2016, p.37).

Pesquisadores europeus também sinalizam esse movimento de comparação entre sistemas de ensino mundiais. Em estudo sobre países da região andina, Pérez, \& Gómez (2004) ressaltam a importância da chamada Educação Intercultural:

Estas propostas são muito significativas e apontam para a Educação Intercultural. Seu progresso é realmente importante, já que a defesa e a reivindicação de escolas representativas de cada cultura reivindicaram desde os anos setenta, progresso para a demanda da incorporação em todas as escolas e para toda a população da diversidade de conteúdos, métodos e tipos de organização que respeitam a diversidade cultural; que, em última análise, força o conhecimento mútuo na estrutura educacional. (Pérez, \& Gómez, 2004, p. 241).

Estudos recentes, como a compilação feita pela Unesco em 2012, ressalta a importância da análise e interpretação dos sistemas educacionais, de modo a refletir sobre a sua origem e essência. Kazamias (2012) aponta para essa direção:

A educação comparada é uma episteme explicativa/interpretativa que busca compreender e interpretar a forma como os sistemas nacionais de educação desenvolveram-se para ser o que são; [...] sistemas nacionais de educação eram a consequência de constelações particulares e únicas de forças, fatores e tradições sociais, políticas, econômicas e culturais. (Kazamias, 2012, p.58).

Justificada a relevância e funcionalidade dos estudos que tomam por base modelos de ensino adotados por países de um mesmo continente, que de certa forma convergem em sua finalidade, é importante caracterizar seus sistemas de ensino para que este trabalho seja fundamentado à luz de suas políticas educacionais.

\subsection{Currículo da Educação Profissional}

No Brasil, a formulação curricular dos cursos de EP de nível médio, objeto deste trabalho, pauta- se na Seção IV, artigo 36, da Lei 9.394 de 1996. O artigo 36-A, da Seção IV-A da mesma Lei, indica, em linhas gerais, o modo da oferta desses cursos.

Sem prejuízo do disposto na Seção IV deste Capítulo, o ensino médio, atendida a formação geral do educando, poderá prepará-lo para o exercício de profissões técnicas.

Parágrafo único. A preparação geral para o trabalho e, facultativamente, a habilitação profissional, poderão ser desenvolvidas nos próprios estabelecimentos de ensino médio ou em cooperação com instituições especializadas em educação profissional. (Brasil, 1996)

Cabe ressaltar que o Ministério da Educação (MEC) publica periodicamente o Catálogo Nacional de Cursos Técnicos (CNCT) - documento em que constam informações relevantes, como as denominações dos cursos e respectivos eixos tecnológicos, perfil profissional de conclusão, infraestrutura mínima, carga horária mínima dos cursos e é atualizado periodicamente para contemplar novas demandas socioeducacionais.

Com relação ao Peru, a lei n. ${ }^{\circ}$ 28044, de 2003, em seu capítulo III, artigo $44^{\circ}$ (Currículo e Avaliação), indica que "cada Centro de Educação Técnico-Produtiva elabora seu projeto institucional e define os currículos 
das diferentes especialidades considerando os requisitos laborais em seu âmbito de atuação, mudanças do entorno, obsolescência da tecnologia, desenvolvimento do conhecimento e características dos estudantes".

Ao identificar a autonomia das instituições de formação profissional, é conclusivo que, embora siga a legislação em vigor, a formulação curricular peruana é dotada de dinamismo e critérios, atendendo às demandas da sociedade e prezando pelas características socioeconômicas existentes.

\subsubsection{Formulação Curricular de Cursos Técnicos de Nível Médio no Ceeteps}

O Currículo de EP de Nível Médio é elemento fundamental na condução dos cursos profissionalizantes. Segundo Araújo, Demai, \& Prata (2016):

O Currículo de Educação Profissional Técnica de Nível Médio é o esquema teórico- metodológico que direciona o planejamento, a sistematização e o desenvolvimento de perfis profissionais, atribuições, atividades, competências, habilidades, bases tecnológicas, valores e conhecimentos, organizados em componentes curriculares e por eixo tecnológico/área de conhecimento, a fim de atender a objetivos de Formação Profissional de Nível Médio, de acordo com as funções do mercado de trabalho e dos processos produtivos e gerenciais, bem como as demandas sociopolíticas e culturais, as relações e atores sociais da escola. (Araújo, Demai, \& Prata, 2016, p. 20).

A instituição brasileira analisada - Ceeteps - é uma autarquia do Governo do Estado de São Paulo, vinculada à Secretaria de Desenvolvimento Econômico, Ciência, Tecnologia e Inovação (SDECTI). Presente em aproximadamente 300 municípios, a instituição administra 221 Escolas Técnicas (Etecs) e 68 Faculdades de Tecnologia (Fatecs) estaduais, ultrapassando o número de 290 mil alunos em cursos técnicos de nível médio e superiores tecnológicos (Ceeteps, 2017).

O Ceeteps conta com um departamento responsável pela construção curricular de seus cursos técnicos, denominado Grupo de Formulação e Análises Curriculares, cuja metodologia obedece a critérios previamente estabelecidos e padronizados, e "ao lado do atendimento à legislação [...], o desenvolvimento e o oferecimento de cursos técnicos em parceria com o setor produtivo/mercado de trabalho tem sido a principal diretriz do planejamento curricular da instituição" (Araújo, Demai, \& Prata, 2016, p.5).

Fazendo-se valer do Convênio Marco de Cooperação Interinstitucional entre o Ceeteps, no Brasil, e o Senati, no Peru, onde declaram sua vontade de participar de forma conjunta em atividades, projetos e programas voltados à geração e transferência de conhecimentos e tecnologías, foram analisadas as metodologias de formulação curricular das duas instituições.

A habilitação profissional contemplada no Ceeteps é o curso Técnico em Administração, oferecido em 297 unidades, entre escolas e classes descentralizadas (parceria com a Secretaria da Educação do Estado de São Paulo), cujo perfil profissional de conclusão prevê o desenvolvimento de várias competências gerais, voltadas principalmente à aplicação de conceitos de gestão, utilização de equipamentos e sistemas específicos, atuação proativa e crítica e ao desenvolvimento de capacidades para elaborar, programar e consolidar projetos em organizações.

As informações obtidas junto ao Ceeteps indicam a preocupação da instituição em formar alunos para o mercado de trabalho, e também apontam para a formação humanística e cidadã do discente, abordando o desenvolvimento de capacidades que ultrapassam o horizonte da sala de aula. Ao mesmo tempo, preza por uma atuação plena no âmbito profissional, não excedendo ao limite de atuação do técnico, mas contribuindo para um aprendizado contínuo durante sua vida.

\subsubsection{Formulação Curricular de Cursos Técnicos de Nível Médio no Senati}

O Senati, instituição de ensino profissional peruana analisada, possui 83 centros de formação e capacitação em 25 regiões do país. Em 2016, contava com aproximadamente 87 mil alunos em cursos de formação profissional, contemplando 70 carreiras (Senati, 2016).

A sua política institucional, lavrada no Acordo sob n. ${ }^{\circ}$. 107-2016 junto ao Conselho Nacional de Educação, descreve várias ações que caracterizam o Senati como centro formador para o mundo do 
trabalho, destacando-se o desenvolvimento de carreiras técnicas de acordo com as necessidades do mercado de trabalho e os requisitos das atividades econômicas da área/região, considerando a Segurança e Saúde Ocupacional e o cuidado do meio ambiente, para contribuir para a geração de potencial técnico humano e melhorar sua empregabilidade e qualidade de vida.

O estudo toma por base o curso de Administração Industrial, que é oferecido em um programa de "Aprendizagem Dual" em 40 unidades, e voltado à formação de jovens entre 14 e 24 anos que concluíram seus estudos secundários e desejam desempenhar atividades relacionadas com tarefas produtivas diretas da indústria. É possível verificar, por parte do Senati, o estabelecimento de parcerias com o setor produtivo, combinando a aprendizagem prática com as instalações produtivas das empresas.

Quando da escrita do perfil do aluno concluinte do curso em questão, a instituição analisada aponta que se trata de um "profissional técnico, capacitado para desempenhar funções técnico- administrativas na gestão de operações, logística e administração geral, melhorando os processos produtivos para criar valor nas empresas industriais" (SENATI, 2017), possuindo competências gerais e específicas para o exercício de suas funções, destacando-se aquelas inerentes à aplicação de instrumentais voltados à gestão empresarial e programas de qualidade, além das atividades contábeis e financeiras. Esta análise incipiente permite concluir que o Senati prima pelo desenvolvimento de habilidades que suportem a atuação do aluno no cotidiano das empresas, proporcionando-lhe pleno desenvolvimento no exercício de suas funções laborais.

\section{DISCUSSÃO E CONCLUSÕES}

A análise preliminar das instituições permite verificar que ambas primam pela relação entre educação e trabalho. A Lei Geral de Educação do Peru, um pouco mais nova que a Lei de Diretrizes e Bases brasileira, objetiva o desenvolvimento de competências profissionais e capacidades empreendedoras nos seus alunos. Também ressaltam a importância das formações humanística e técnica dos discentes, além dos preceitos da educação por competências, denotando a preocupação em preparar o cidadão para não apenas o mercado, mas para o mundo do trabalho em constante e incisiva evolução.

Em ambos os cenários é possível notar o conhecimento como delineador das práticas de cada país, demonstrando o propósito de se educar para um mercado cada vez mais exigente e conectado, quer seja pelo ensino vocacionado ou pela disseminação da EPT. Detecta-se, também, a preocupação com a garantia de aderência de seus cursos ao mercado de trabalho, contemplando os anseios do setor produtivo e a formação do cidadão.

O intercâmbio de práticas adotadas por países vizinhos, dado o crescente avanço tecnológico mundialmente experimentado, é válido e pode definir um estudo comparativo mais completo, direcionado a um país cuja proximidade e similaridade de aspectos sociais podem contribuir com a gestão da EPT brasileira.

Estudos recentes apontam para modelos de sucesso difundidos em países como Finlândia e Coreia do Sul, mas que se mostram por vezes limitados à aplicação em suas nações. Por consequência, a análise de práticas de países do continente sul americano pode consistir em experiência válida quando da concepção do ensino profissionalizante, dada as características das instituições que ofertam essa modalidade de educação.

Legitima a proposta deste trabalho a possível transformação da realidade por intermédio de práticas comuns aos países contemplados na pesquisa, com projetos inovadores na concepção de currículos cada vez mais adequados às exigências da sociedade, pautados na constante atuação junto aos diversos atores, como empresas, entidades de classe, demais instituições de ensino, com foco na realização de parcerias que fortaleçam o desenvolvimento da EPT em âmbito continental. 


\section{REFERÊNCIAS BIBLIOGRÁFICAS}

Araújo, A. M. de (2015). Currículos e Programas do Ensino Técnico no Brasil: décadas de 1970 a 2010. In Carvalho, M. L. M. de (Ed.), Patrimônio Artístico, Histórico e Tecnológico da Educação Profissional, p.15. São paulo: Centro Paula Souza.

Araújo, A. M. de, Demai, F. M., \& Prata, M. (2016). Missão, Concepções e Práticas do Grupo de Formulação e Análises Curriculares (Gfac): uma síntese do Laboratório de Currículo do Centro Paula Souza. Recuperado de: http://www. cpscetec.com.br/cpscetec/arquivos/2014/missao.pdf.

Brandão, C. da F. (2011). O Ensino Profissional no Plano Nacional de Educação: as questões da oferta, do atendimento e da formação profissional. Camine: Caminhos da Educação, 1, pp. 1-13. Recuperado de: http://hdl.handle. net/11449/126892.

Brasil, Constituição da República Federativa de 1937. Recuperado de: https://www.jusbrasil.com.br/topicos/10614355/artigo-129-da-constituicao-federal-de- 10-de-novembro-de-1937.

Brasil, Constituição da República Federativa de 1988. Brasil, Lei 5.692, de 11 de agosto de 1971.

Brasil, Lei 7.044 de 18 de outubro de 1982.

Brasil, Lei de Diretrizes e Bases da Educação Nacional n 9.394.

Centro Estadual de Educação Tecnológica Paula Souza. Recuperado de: http://www.cps.sp.gov.br/perfil-e-historico.

Kazamias, A. M. (2012). Homens Esquecidos, Temas Esquecidos: os temas histórico-filosófico- culturais e liberais humanistas em educação comparada. In Cowen, R, Kazamias, A. M., \& Ulterhalter, E. (Ed.), Educação Comparada: panorama internacional e perspectivas, p.58. Brasília: Unesco, Capes.

Luna, J. M. F. de (2016). Internacionalização do Currículo e Educação Intercultural: aproximações à luz da sociologia das ausências e da sociologia das emergências. In Luna, J. M. F. (Ed.), Internacionalização do currículo: educação, interculturalidade, cidadania global, p.37. Campinas: Pontes Editores.

Moraes, C. S. V. (1996). Ensino Médio e Qualificação Profissional: uma perspectiva histórica. In Bruno, L. (Ed.), Educação e Trabalho no Capitalismo Contemporâneo: leituras selecionadas, p. 131. São Paulo: Atlas.

Pérez, I. G., \& Gómez, M. G. de la T. (2004). La Cooperación Educativa Internacional Ante la Diversidad Cultural: um estúdio comparativo em la región andina. Revista Española de Educación Comparada, 10, pp. 237-273. Recuperado de: http://revistas.uned.es/index.php/REEC/article/view/7395/7063.

Peru, Ministério da Educação. Lei n. ․ 28.044/03. Recuperado de: http://www.minedu.gob.pe/.

São Paulo (2017). Convênio Marco de Cooperação Interinstitucional Entre o Centro Estadual de Educação Tecnológica Paula Souza - Ceeteps de São Paulo - Brasil e o Serviço Nacional de Treinamento em Trabalho Industrial - Senati de Lima - Perú. Diário Oficial do Estado de São Paulo, Poder Executivo - Seção I, 14 de julho de 2017, p.127.

Saviani, D. (2016). Educação Escolar, Currículo e Sociedade: o problema da base nacional comum curricular. Movimento Revista de Educação, 4, p.55. Recuperado de: http://www.revistamovimento.uff.br/index.php/revistamovimento/article/view/296/301.

Senati - Serviço Nacional de Adestramento em Trabalho Industrial. Recuperado de: http://www.senati.edu.pe/web/institucional/politica-institucional.

Senati - Serviço Nacional de Adestramento em Trabalho Industrial. Memória Anual 2016. Recuperado de: http://www.senati. edu.pe/sites/default/files/archivos/2017/publicaciones/09/senati_memoria_2016.pdf. 